\title{
Daily Versus Weekly Oral Iron Supplementation in Pregnant Women : A Randomized Controlled Clinical Trial
}

Original Article

\author{
Magdy Abdelgawad, Dina Mansour, Mohammed Mohammed
}

Department of Obstetrics and Gynecology, Faculty of Medicine, Ain-Shams University, Egypt

\begin{abstract}
Background: High doses of iron lead to gastrointestinal intolerance suggesting some toxic effect on the gut mucosa that is probably mediated by iron-related oxidative stress.

Aim : This study aimed to compare the hemoglobin levels in non anemic pregnant women receiving weekly versus daily iron supplementation.

Material and Methods: This randomized controlled clinical trial was conducted One hundred and forty patients during the period from October 20017 to December 2018 at Ain-Shams University Maternity Hospital in the outpatient antenatal clinics. They were divided into two groups; group A (weekly group) received 2 capsules of $100 \mathrm{mg}$ elemental iron (from 305 $\mathrm{mg}$ ferrous fumarate) plus $2 \mathrm{mg}$ of folic acid (Ferro-6-Pharco- Egypt) once weekly and group B (daily group) received one capsule of $100 \mathrm{mg}$ elemental iron (from $305 \mathrm{mg}$ ferrous fumarate) plus $2 \mathrm{mg}$ of folic acid (Ferro-6-Pharco-Egypt) once daily. Results: There was no statistically significant difference could be detected between both groups as regards the demographic data, body mass index, interval since last pregnancy, hemoglobin level before starting iron supplementation and duration of supplementation and this can be attributed to proper randomization. In this study, there was no statistically significant difference between both groups as regards the hemoglobin level after one month of iron supplementation and after three months of iron supplementation. Although the mean hemoglobin concentration at 36 weeks gestation was lower in the weekly supplementation group it did not reach the level of statistical significance. There was significant increase in the incidence of iron side-effects mainly gastrointestinal side-effects in the form of nausea, vomiting, constipation, heart burn and metallic taste. High doses of iron lead to gastrointestinal intolerance. There was no statistically significant difference could be detected between both groups as regards the fetal weight.

Conclusion: Weekly iron supplementation as a prophylaxis in non-anemic pregnant women is as good as daily supplementation as regards the hemoglobin level in addition; it was associated with significantly fewer side-effects and much better compliance.
\end{abstract}

Key Words: Dose, oral iron supplementation, pregnancy

Received: 29 September 2019, Accepted: 30 September 2019

Corresponding Author: Magdy Abdelgawad, Department of Obstetrics and Gynecology, Faculty of Medicine, Ain-Shams University, Cairo Tel.: 01069491030,E-mail: magdyabdelgawwad@gmail.com

ISSN: 2090-7265, May 2021, Vol.11, No. 2

\section{INTRODUCTION}

It is estimated that $38.2 \%$ of pregnant women are anemic worldwide ${ }^{[1]}$, which translates to 32.4 million pregnant women. Half of the global anemia prevalence is assumed to be due to iron deficiency in non-malaria areas ${ }^{[2]}$.

Anemia during pregnancy is diagnosed if a woman's hemoglobin $(\mathrm{Hb})$ concentration at sea level is lower than $11 \mathrm{~g} / \mathrm{dL}$, although it is recognised that during the second trimester of pregnancy, $\mathrm{Hb}$ concentrations diminish by approximately $0.5 \mathrm{~g} / \mathrm{L}^{[3]}$. This is due to iron deficit intake of diet that could not meet the increased iron demand for the developing fetus ${ }^{[4]}$.

Regulation of iron is a highly sophisticated phenomenon where its imbalance could result into significant morbidity and mortality. The disturbed intricate balance during iron regulation may either result in iron deficiency or iron overload, out of which iron deficiency is most commonly observed $^{[4]}$.
The most common strategy for the management of this staggering situation is to start oral iron supplementation during pregnancy. Iron consumption for pregnant women is undesirable, because of the side effects. The probable cause is the effect of oxidative stress of high doses of Iron, which leads to gastrointestinal intolerance ${ }^{[5]}$.

Exposing intestinal cells to supplemental iron less frequently, (e.g. every week in synchrony with the human mucosal turnover that occurs every five to six days) may improve the efficiency of absorption since the mucosal cells are not "blocked" by large amounts of iron as may occur with daily iron intake ${ }^{[6]}$.

Significant equality and reduced side effects have been reported in several epidemiological studies in comparing the weekly prescription of iron with daily supplementation ${ }^{[5]}$. Thus, weekly rather than daily administration of iron has been proposed as a safe, beneficent, and cost-effective method to prevent and alleviate anemia in pregnant women ${ }^{[7]}$. 
Intermittent oral iron supplementation (i.e. one, two or three times a week on non-consecutive days) is recommended as an alternative to daily iron supplementation in pregnant women ${ }^{[8]}$.

\section{AIM OF THE WORK}

This study aims to assess the efficacy and tolerability of weekly versus daily oral iron supplementation in pregnant women.

\section{PATIENTS AND METHODS}

This study was designed as a randomized controlled clinical trial during the period from October 2017 to December 2018. The study was conducted in Ain-Shams University Maternity hospital in the outpatient antenatal clinics. One hundred and forty (140) patients were randomly assigned through a computer generated randomization sheet to receive oral iron supplementation either daily or weekly.

\section{Inclusion and exclusion criteria:}

The study included pregnant women between 13 and 20 weeks of gestation, no prior intake of iron supplements in the current pregnancy and hemoglobin level > $11 \mathrm{~g}$ ML.

While patients with hemoglobin level $<11$ g ML, History of chronic renal disease, History of chronic liver disease, Chronic peptic ulcer, Bleeding piles, Known Thalassamia and other hemoglobinopathies, Multifetal pregnancies, History of prior blood transfusion in the current pregnancy, History of obstetric hemorrhage in the present or past pregnancies and pregnant women who cannot tolerate oral iron intake were excluded from the study.

All patients were subjected to the following during the first visit informed written consent was taken from all patients involved in the research and then complete history was taken from them involving detailed dietetic history as the following:

History including: personal history: Age. Special habits. Address, social class, endemic areas of diseases, dietetic habits regarding intake of iron containing foods such as: Meat, fishes, poultry, fruits, molasses and cereals. Obstetric history: Parity. Intervals between deliveries. Complications during the present or past pregnancies and deliveries. Contraceptive methods, duration and complication. Menstrual history: date of last menstrual period, amount, duration, frequencies, menarche, and inter menstrual bleeding. Past history: History of chronic renal disease. History of chronic liver disease. History of chronic peptic ulcer. Bleeding piles or any source of bleeding,

Known Thalassamia and other hemoglobinopathies. History of prior blood transfusion in the current pregnancy. History of obstetric hemorrhage in the present or past pregnancies. History of oral iron intake. History of blood donation.
Present history: Bleeding during the current pregnancy. Multifetal pregnancies. II. Clinical Examination: Weight, height, nails, lips, peticheal hemorrhage, tongue, skin (color, elasticity), splenomegaly, hemic murmur and water hummer pulse. III. Investigations: Complete blood count (CBC), $2 \mathrm{ml}$ of venous blood were collected on EDTA vacutainers. Ultrasound. To exclude multifetal pregnancy. To exclude placenta previa. To confirm gestational age. Routine antenatal investigations. After taking an informed consent, all participants were randomly assigned to either group by computer- generated selection using consecutively numbered sealed envelopes; group A (weekly group) received 2 capsules of $100 \mathrm{mg}$ elemental iron (from $305 \mathrm{mg}$ ferrous fumarate) plus $2 \mathrm{mg}$ of folic acid (Ferro-6-Pharco- Egypt) once weekly and group B daily group) received one capsule of $100 \mathrm{mg}$ elemental iron (from $305 \mathrm{mg}$ ferrous fumarate) plus $2 \mathrm{mg}$ of folic acid (Ferro-6- Pharco-Egypt) once daily.

Iron supplementation started between 14 and 20 weeks of the gestation and continued until delivery.

Women in the daily supplementation group were instructed to take one capsule daily and supplied with three blister packets (total 30 capsules) for one month.

Women in the weekly supplementation group were supplied one blister packets (10 capsules) to cover one month. They were instructed to choose any day of the week and to take two capsules on that day, one before lunch and the other before dinner (total of 200mg elemental iron / week). No capsules were given for the rest of the week, this regimen was repeated weekly.

All women were instructed to take iron capsules 30 minutes before meals and not to take them with coffee, tea or milk. They were also advised to take calcium supplements after meals. Health education regarding the importance of diet in pregnancy, iron-rich food and appropriate dietary practices was given to all.

Patients were informed about the usual side effects of iron preparations and told to report nausea, vomiting, bowel disturbances or any other complications.

They were also instructed to report if sever intolerance caused them to stop taking supplements. Patients also were instructed to bring back the empty packets or strips of capsules in each visit and the total number of capsules consumed during pregnancy was calculated for each patient

Follow up visit were arranged in the same antenatal clinic every month till 32 weeks then every 2 weeks till 36 weeks then weekly till delivery.

Symptoms related to iron intake e.g.; nausea, vomiting and bowel disturbances ........ etc, were recorded in the weekly supplementation group during the 24 hours after the intake.

$\mathrm{CBC}$ was done after one and three months from starting supplementation and a final one was done at 36 weeks of gestation. 


\section{STATISTICAL ANALYSIS}

Analysis of data was done by IBM computer using SPSS (statistical program for social science version 12) as follows: Descriptive data of quantitative parametric variables are expressed as mean, $\pm \mathrm{SD}$ and range Description of non parametric variables as number and percentage Chisquare test was used to compare non parametric variables between the two groups. Fisher exact test was used instead of chi-square test when one expected cell or more less than 5. Unpaired t-test was used to compare parametric variables, in parametric data between the two groups. Paired t-test was used to compare quantities variables in the same group before and after treatment; $P$ value $>0.05$ insignificant and $P$ value $<0.05$ significant.

\section{RESULTS}

Table 1 showed no statistically significant difference detected between both groups as regard (demographic data): maternal age, gestational age and parity and (characteristics): body mass index, interval since last pregnancy and duration of supplementation.

The two groups were matched for the hemoglobin level before starting, during and at 36 weeks of gestation with iron supplementation the results were shown in table 4 .

Table 2 showed no statistically significant difference between both groups as regard $\mathrm{Hb}$ level before starting iron supplementation, after one month, after three months and at 36 weeks of gestation with iron supplementation by using unpaired t- test.
The two groups were matched for the patients with hemoglobin level equal to $10 \mathrm{~g} / \mathrm{dL}$ or less and the results shown in table 5 .

Table 3 showed that weekly group had higher frequency of $\mathrm{Hb}$ level less than 10 compared to daily dose group but without significant statistically difference between both groups by using Fisher exact test.

The two groups were matched for the frequency of the side effects of iron supplementation in all days in the daily group and the day after iron intake in the weekly group the results shown in table 6 .

Table 4 showed that there were statistically significant differences between both groups as regards all side effects of iron supplementation being more in group B.

The number of patients whom did not suffer from any side effects were (56) patient in the weekly group compared to (29) patient in the daily group with highly significant statistically difference between both groups $(p<0.001)$

Table 5 showed that weekly group defaulters were less than daily group with statistically significant difference in between both groups and also shows that weekly group compliance with supplements were more than daily group with statistically highly significant difference in between both groups by using Fisher exact test.

Table 6 showed no statistically significant difference between both groups as regard fetal weight by using Fisher exact test.

Table 1: Comparison between both groups as regard demographic data and characteristics

\begin{tabular}{|c|c|c|c|}
\hline & $\begin{array}{c}\text { Group A } \\
\mathrm{N}=67\end{array}$ & $\begin{array}{c}\text { Group B } \\
\text { N-58 }\end{array}$ & $P$ \\
\hline * Maternal age (years) & $22.7 \pm 3.9$ & $22.4 \pm 3.8$ & 0.6656 \\
\hline *Gestational age(weeks) & $16.6 \pm 2$ & $15.8 \pm 3.7$ & 0.1284 \\
\hline **Parity & $1(0-3)$ & $1(0-2)$ & 0.4871 \\
\hline * Body mass index $\left(\mathrm{kg} / \mathrm{m}^{2}\right)$ & $26.5 \pm 2.0$ & $27 \pm 2.3$ & 0.1960 \\
\hline * Interval since last pregnancy (months) & $20.1 \pm 7.8$ & $19.1 \pm 12.1$ & 0.5791 \\
\hline * Duration of supplementation (weeks) & $18.2 \pm 2.2$ & $17.9 \pm 1.7$ & 0.4008 \\
\hline
\end{tabular}

*Data are given as mean $\pm \mathrm{SD} * *$ Data are given as median (range).

Table 2: Comparison between both group level Hb before starting iron supplementation, after one month, after three months and at 36 weeks of gestation with iron supplementation

\begin{tabular}{cccc}
\hline$*$ Hb level $(\mathrm{g} / \mathrm{dL})$ & Group A & Group B & N=58 \\
\hline Baseline & $11.47 \pm 0.6$ & $11.51 \pm 0.7$ & 0.7314 \\
After one month & $11.44 \pm 0.6$ & $11.68 \pm 1.1$ & $11.1 \pm 0.8$ \\
After three months & $10.8 \pm 1$ & 0.0965 & 0.0693 \\
Final at 36 weeks & & $11.1 \pm 0.7$ & 0.1729 \\
\hline
\end{tabular}

*Values are expressed as mean $\pm \mathrm{SD}$. 
Table 3: Comparison between both groups as regard $\mathrm{Hb}$ level $<10 \mathrm{~g} / \mathrm{dL}$ at 36 weeks

\begin{tabular}{cccc}
\hline Hb level & Group A & Group B & $p$ \\
\hline$<10 \mathrm{~g} / \mathrm{Dl}$ & $\mathrm{N}=67$ & $\mathrm{~N}=58$ & $1(1.7)$ \\
$>10 \mathrm{~g} / \mathrm{dL}$ & $6(10.4 \%)$ & $57(98.3 \%)$ & 0.1053 \\
\hline
\end{tabular}

Table 4: Comparison between both groups as regard side effects of iron supplementation

\begin{tabular}{cccc}
\hline Side effects & Group A & Group B & $P$ \\
\hline Nausea & N=67 & N-58 & $11(17.2 \%)$ \\
Heart burn & $3(4.4 \%)$ & $12(20.6 \%)$ & 0.0404 \\
Constipation & $4(5.9 \%)$ & $9(15.5 \%)$ & 0.0285 \\
Metallic taste & 0 & $13(22.4 \%)$ & 0.0027 \\
\hline
\end{tabular}

Table 5: Comparison between both groups as regard (1) cases stopped iron supplementation due to gastrointestinal side effects of oral iron, (2) Compliance in either groups or (the number of women who took $90 \%$ or more of all the required tablets until deliver)

\begin{tabular}{cccc}
\hline Defaulters & Group A & Group B & $P$ \\
\hline No (1) & 3 & 12 & 0.0278 \\
$\%$ & $4.2 \%$ & $17.1 \%$ & $<0.001$ \\
No (2) & 60 & 19 & $32.7 \%$ \\
$\%$ & $89.5 \%$ & & \\
\hline
\end{tabular}

Table 6: Comparison between both groups as regard fetal weight at 36 weeks

\begin{tabular}{|c|c|c|c|}
\hline Fetal weight & $\begin{array}{c}\text { Group A } \\
\mathrm{N}=67\end{array}$ & $\begin{array}{c}\text { Group B } \\
\mathrm{N}=58\end{array}$ & $P$ \\
\hline$<2.5 \mathrm{~kg}$ & $5(7.5 \%)$ & $4(6.9 \%)$ & \multirow{2}{*}{0.828} \\
\hline$>2.5 \mathrm{~kg}$ & $62(92.5 \%)$ & $54(93.1 \%)$ & \\
\hline
\end{tabular}

\section{DISCUSSION}

The aim of this study was to compare the hemoglobin levels in non-anemic pregnant women receiving weekly versus daily iron supplementation.

Ethical consideration prevents the enrollment of placebo group. Anemic pregnant patients (Hemoglobin level $<11 \mathrm{~g} / \mathrm{dL}$ ) were excluded from this study for patient's safety.

Two groups were matched and there were no statistically' significant difference could be detected between both groups as regard maternal age, gestational age and parity (demographic data); body mass index, interval since last pregnancy, hemoglobin level before starting iron supplementation and duration of supplementation and this can be attributed to proper randomization.

There was no statistically significant difference that could be detected between both groups as regards the hemoglobin level after one month, after three months of iron supplementation and although the mean hemoglobin concentration at 36 weeks gestation was lower in the weekly supplementation group than in the daily group, it did not reach the level of statistical significance.

The above results can be explained by the mucosal block theory. It has been suggested that saturation of iron binding protein, apoferritin, in the mucosal cells is the rate limiting step of further absorption of iron. A study in rats also demonstrated more efficient iron absorption if iron is given every three days, the mucosal removal time, rather than daily ${ }^{[9]}$. Since the mucosal turnover time in humans is $5-6$ days, the strategy of weekly iron supplementation has been strongly suggested ${ }^{[10]}$.

Weekly iron supplementation has been tried in some populations, with equal or suboptimal benefits compared with those of daily iron supplementation ${ }^{[11]}$. Since the effectiveness of large scale supplementation programs has never been established, the International Nutritional Anemia Consultative Group, WHO and UNICEF are considering the option of intermittent iron supplementation as a therapeutic protocol ${ }^{[12]}$.

Beaton and $\mathrm{McCabe}$, in a meta analysis of 21 published and unpublished studies regarding daily versus intermittent 
iron supplementation in various population, found that there was a higher final hemoglobin concentration associated with the daily administration of iron ${ }^{[13]}$.

From India, Gomber et al. ${ }^{[10]}$ recently studied daily versus weekly iron supplements in 80 pregnant women and concluded that weekly supplementation was as effective as daily. However, only 56 women had been followed up until the time of final analysis and the women were predominantly non anemic at the time of recruitment ${ }^{[10,14]}$.

A similar study was done by Casanueva et $a l^{[13]}$ and concluded that mild anemia and hypoferritinemia throughout pregnancy occurred less frequently in the daily supplementation than in the weekly supplementation, however non of the 116 women participated in the study had hemoglobin concentration $<103 \mathrm{~g} / \mathrm{L}$ at any evaluation point. In contrast, hemoconcentration ( $\mathrm{Hb}>145 \mathrm{~g} / \mathrm{L})$ from gestational week 28 onward occurred in $11 \%$ in the daily supplementation group and $2 \%$ in the weekly supplementation group and there was a significant association between hemoconcentration and low birth weight and preterm delivery.

In our study hemoglobin level less than $10 \mathrm{~g} / \mathrm{dL}$ at 36 weeks gestation occurred in $10.4 \%$ in the weekly group versus $1.7 \%$ in the daily group with no statistically significant difference in between both groups, however such difference was not demonstrated in Casanueva et al. ${ }^{[13]}$.

There was significant increase in the incidence of iron side effects, mainly gastrointestinal side effects, in the form of nausea, constipation, heart burn and metallic taste. High doses of iron lead to gastrointestinal intolerance, suggesting some -toxic effects on the gut mucosa that is probably mediated by iron-related oxidative stress. Large doses of iron are also associated with a reduction in the absorption of other elements such as zinc ${ }^{[15]}$.

In this study, the higher incidence of gastrointestinal side effects was reflected on the compliance in spite of the appropriate information given initially to all patients and monthly reinforcement during routine antenatal visits. In the weekly supplementation group all women were instructed to do not wait for a week to take the next supplement if they forget to take the tablets on the selected day, and that they should take it as soon as they become aware of the omission.

In this study, 60 women out of 67 in the weekly group were reported taking more than $90 \%$ of the required tablets compared to 19 women out of 58 in the daily group, and this was checked verbally and by inspecting the blister packets. In Mukhopadhyay et al. ${ }^{[16]}$, study, $60 \%$ of women in the daily group were non-compliant and gastrointestinal side-effects were responsible for this in $75 \%$ of cases. In the weekly group, only $15 \%$ did not comply with the prescribed schedule, the major reason being forgetting to take iron pills after an interval of a week.
Several studies show that anemia occurring during pregnancy increases 'the risk of low birth weight and / or premature delivery ${ }^{[17]}$.

Intermittent iron supplementation therapy is also being applied to other iron-deficient groups, such as young children and women of childbearing age, with the aim of improving iron nutrition. The rationale for its use by women of reproductive age is for prevention, whereby the long-term application of intermittent therapy will ensure that women enter pregnancy with adequate iron reserves. Such a program of preventive supplementation is similar in aim to the WHO recommendation that supplemental iron be given to adolescents and women in vulnerable populations for $2-4 \mathrm{mo} / \mathrm{y}^{[18]}$.

In a study by Bhargava et al. ${ }^{[19]}$ conducted under a similar setting, the prevalence of anemia in pregnancy was $30 \%$ in the urban area of Delhi. Mild anemia in pregnancy was not related to an increased incidence of preterm or low birth weight babies, although babies born to severely anemic mothers did have lower birth weights and shorter gestation. The level was $24.81 \mathrm{ng} / \mathrm{mL}^{[20]}$.

Goonewardene et al. ${ }^{[21]}$ compared the effectiveness of weekly, thrice weekly and daily oral iron supplementation in the prevention of IDA of pregnancy. They recommended daily oral iron supplementation for pregnant women in communities at risk of IDA. Intermittent iron supplementation appears to be inappropriate ${ }^{[22]}$.

Ziauddin Hyder et al. ${ }^{[23]}$ investigated whether iron supplementation during pregnancy and puerperium has a dose effect on haemoglobin 6 weeks after delivery, and whether there is any differential effect between daily and weekly regimens at 6 weeks postpartum. They concluded that effects of iron supplementation in pregnancy and puerperium were observed at 6 weeks after delivery. The size of the effect was dependent on the number of tablets, not on daily or weekly regimen ${ }^{[20]}$.

Mukhopadhyay et al. ${ }^{[16]}$ compared the effect of weekly versus daily iron supplements on the hematological and the pregnancy outcomes. Weekly supplements as a prophylaxis are as good as daily in terms of hemoglobin rise or perinatal outcome. In fact, there were significantly fewer side-effects and patients were happier and more compliant with the weekly regimen. However, in anemic women, even those with mild anemia, daily supplementation appears to be superior to weekly and the serum ferritin level was lower in the weekly supplemented group compared with that in the daily group ${ }^{[16]}$.

Bouzari et al. ${ }^{[22]}$ compared the effects of daily iron supplementation in three time frames- daily, weekly and three time weekly supplementation in preventing anemia in healthy pregnant women. They suggested that three times a week or weekly iron supplementation is as effective as daily supplementation for healthy pregnant women without anemia. 
It is important to denote that this study and most of other studies lack the power to draw any conclusion regarding the difference in fetal weight in both groups.

\section{CONCLUSION}

Weekly iron supplementation as a prophylaxis in nonanemic pregnant women is as good as daily supplementation as regards the hemoglobin level in addition; it was associated with significantly fewer side-effects and much better compliance.

\section{CONFLICTS OF INTERESR}

There are no conflict of interests.

\section{REFERENCES}

1. World Health Organization (WHO), (2015): Hemoglobin concentrations for the diagnosis of anemia andassessmentofseverity.VitaminandMineralNutrition Information System . Cochrane Database Syst Rev., 10.1002/14651858.CD009997.pub2.

2. Stevens GA, Finucane MM, De-Regil LM, Paciorek CJ, Flaxman SR, Branca F, et al., (2013): Global, regional, and national trends in hemoglobin concentration and prevalence of total and severe anemia in children and pregnant and non-pregnant women for 1995-2011: a systematic analysis of population-representative data. Lancet Global Health .1(1):e16-25.

3. World Health Organization(WHO), (2011): The global prevalence of anemia in 2011. Geneva: World Health Organization. Cochrane Database Syst Rev.,110.1002/14651858.CD009997.pub2.

4. Zimmermann MB and Hurrell RF, (2007): Nutritional iron deficiency. Lancet 370,511-520.

5. Schaefer RM, Huch R, Krafft A and Rev Med suisse, (2007): Current recommendations for the treatment of iron deficiency anemia.;3:874-880, 3(105):874-80.

6. Anderson GJ, Frazer DM, McKie AT, Vulpe CD, Smith A. Mechanisms of haem and non-haem iron absorption: lessons from inherited disorders of iron metabolism. Biometals. 2005; 18(4):339-48.

7. Aslinia F, Mazza JJ, Yale SH. Megaloblastic anemia and other causes of macrocytosis. Clin Med Res. 2006;4(3):236-41

8. World Health Organization (WHO), (2012): Daily iron and folic acid supplementation in pregnant women. Geneva:.WHO guidelines, Cochrane Database Sy Rev.,10.1002/14651858.CD009997.pub2.
9. Pena-Rosas JP, Viteri FE. Cochrane Database Syst Rev 2009; 7:(4).

10. Gomber S,Agarwal KN, Mahajan C,Agarwal N. Impact of daily versus weekly hematinic supplementation on anemia in pregnant women. Indian Pediatr 2002; 39 : 339-346.

11. Mumtaz Z, Shahab S, Butt N, Rab MA, DeMuynck A. Daily iron supplementation is more effective than twice weekly iron supplementation in pregnant women in Pakistan in a randomized double-blind clinical trial. The Journal of nutrition. 2000 Nov 1;130(11):2697702 .

12. Osungbade KO, Oladunjoye AO. Preventive treatments of iron deficiency anaemia in pregnancy: a review of their effectiveness and implications for health system strengthening. Journal of pregnancy. 2012;2012.

13. Casanueva E, Viteri FE, Mares-Galindo M, MezaCamacho C, Loría A, Schnaas L, Valdés-Ramos R. Weekly iron as a safe alternative to daily supplementation for nonanemic pregnant women. Archives of medical research. 2006 Jul 1;37(5):67482.

14. Demuth IR, Martin A, Weissenborn A. Iron supplementation during pregnancy - a cross-sectional study undertaken in four Germanstates. BMC Pregnancy Childbirth. 2018;18(1):491.

15. Lachili B, Hininger I, Faure H, Arnaud J, Richard MJ, Favier A, Roussel AM. Increased lipid peroxidation in pregnant women after iron and vitamin $\mathrm{C}$ supplementation. Biological trace element research. 2001 Nov 1;83(2):103-10.

16. Mukhopadhyay A, Bhatla N, Kriplani A, Pandey RM and Saxena R, (2004): Daily versus intermittent iron supplementation in pregnant women. Hematological and pregnancy outcome. J Obstet Gynaecol Res., 30: 409-417.

17. Scholl TO, Reilly T. Anemia, iron and pregnancy outcome. The Journal of nutrition. $2000 \mathrm{Feb}$ $1 ; 130(2): 443 \mathrm{~S}-7 \mathrm{~S}$.

18. Peña-Rosas JP, De-Regil LM, Dowswell T, Viteri FE. Intermittent oral iron supplementation during pregnancy. Cochrane Database Syst Rev. 2012;(7):CD009997.

19. Bhargava M, Iyer PU, Kumar R. Relationship of 
maternal serum ferritin with foetal serum ferritin, birth weight and gestation. J Trop Pediatr 1991; 37: 149-152.

20. Peña-Rosas JP, De-Regil LM, Garcia-Casal MN, Dowswell T. Daily oral iron supplementation during pregnancy. Cochrane Database Syst Rev. 2015;(7):CD004736.

21. Goonewardene M, Liyanage C, Fernando R. Intermittent oral iron supplementation during pregnancy. Ceylon Med J. 2001; 46(4): 132-5..
22. Bouzari Z, Basirat Z, Zeinal Zadeh M, Cherati SY, Ardebil MD, Mohammadnetaj M, Barat S. Daily versus intermittent iron supplementation in pregnant women. BMC Res Notes. 2011 Oct 25;4:444.

23. Ziauddin Hyder SM, Persson LA, Chowdhury AMR, Lo"nnerdal B, and Ekstro"m EC. Impact of daily and weekly iron supplementation to women in pregnancy and puerperium on haemoglobin and iron status six weeks postpartum: results from a communitybased study in Bangladesh. Scandinavian Journal of Nutrition 2003; 47 (1): 19-25. 